\title{
Há espaço para o ensino de Inglês para crianças no currículo de cursos de Letras Português- Inglês?
}

\section{Is there room for the teaching of English to children in languages college course's curriculum?}

\author{
Dayane Rita de Souza Cirino ${ }^{1}$, Didie Ana Ceni Denardi ${ }^{2}$
}

\section{Resumo}

\begin{abstract}
Novos contextos de ensino de Língua Inglesa manifestam-se na contemporaneidade. Entre eles, o ensino de Inglês para crianças tem crescido consideravelmente nos últimos anos. No entanto, parece haver uma lacuna na formação de professores de Inglês, já que os Cursos de Letras Português- Inglês preparam professores para ministrar aulas de Inglês para os quatro anos finais do Ensino Fundamental II e para os três anos do Ensino Médio, enquanto que o Curso de Pedagogia tem a finalidade de formar professores para atuarem na Educação Infantil, primeiros quatro anos do Ensino Fundamental I, nas disciplinas do currículo geral, mas não para o ensino dessa língua estrangeira (FERNANDEZ; RINALDI, 2009). Considerando tais constatações, nos perguntamos: a) Poderia ser o Curso de LetrasInglês o responsável para formar professores de Inglês para crianças?; b) Até que ponto, os currículos dos Cursos de Letras-Inglês estão contribuindo efetivamente para novas práticas em sala de aula? Neste sentido, o presente artigo tem por objetivo apresentar uma análise de currículos de dois Cursos de Letras Português-Inglês de Instituições Federais de Ensino localizadas no Sudoeste do Paraná, procurando identificar, caso possível, espaços que possam comtemplar o ensino-aprendizagem de Inglês para a educação infantil.
\end{abstract}

Palavras-chave: Formação do professor. Currículo. Ensino-aprendizagem de Inglês.

\begin{abstract}
New English teaching contexts are being manifested in our time. Teaching English for kids has grown significantly in recent years. Although, it seems there is a gap in the English teacher's education because English/ Portuguese Language Courses prepare teachers to teach English for the four final years on Elementary School II and the three levels on High School, while the Pedagogy Course has the aim to educate teachers who work at Children Education, , first four years of Elementary School I, with general subjects, but not to teach this foreign language (FERNANDEZ; RINALDI, 2009). Considerng these complains, we question: a) Could it be Language Course the responsable to educate English teachers to children?; b) To what extent, are the Language Course curriculums effectively contributing for new practices in the classrooms?;Therefore,, this article has as an objective to present an analysis of two curriculums of two Language Courses of Federal Institutions located in the southwest Paraná, attempting to identify, it it is possible, rooms which cane the English teaching/learning for Children Education.
\end{abstract}

Key words: Teacher education. Curriculum. English teaching and learning.

\footnotetext{
1 Mestranda no Programa de Pós-Graduação em Letras (PPGL) pela Universidade Tecnológica Federal do Paraná - UTFPR. E-mail: dayasouza@hotmail.com

2 Pós-doutorado em Estudos Linguísticos pelo Programa de Pós-Graduação em Inglês da Universidade Federal de Santa Catarina. Professora da Universidade Tecnológica Federal do Paraná - Campus Pato Branco.
} 


\section{Introdução}

O ensino e a aprendizagem de um novo idioma, diferentemente do que muitos acreditam data de longo tempo. De acordo com Nogueira (2007), a partir de 1530, quando o aventureiro britânico Willian Hawkins desembarcou na costa brasileira, inúmeros conterrâneos seguiram o mesmo caminho e vieram tentar a vida e buscar uma das riquezas da terra: o pau-brasil.

Porém, foino anode 1654 quando orelacionamento entre Brasil e Inglaterra se estreitaram ao firmar um tratado com a marinha britânica, rompendo o domínio colonial português no Brasil, que os ingleses foram autorizados a estabelecer suas casas comerciais e passaram a exercer forte influência no Brasil. Segundo Dias (1999), no início do século XIX, mais de 30 estabelecimentos comerciais ingleses foram criados no Brasil e abriram vagas para contratação. Assim, foi necessário que a população que aqui vivia dominasse o idioma falado pelos empregadores para que pudesse se comunicar e compreender comandos e instruções.

Foi então no ano de 1809 que o ensino formal de inglês teve início com um decreto do Príncipe regente de Portugal que mandou criar uma escola de língua francesa e outra de língua inglesa e a partir daí começaram a surgir os primeiros professores de Inglês no Brasil.

$\mathrm{O}$ ensino de inglês e francês durante o império sofria de um grave problema: a falta de uma metodologia adequada. De acordo com Leffa (1999, p. 3), "a metodologia para o ensino das chamadas línguas vivas era a mesma das línguas mortas (e.g. latim): tradução de texto e análise gramatical".

Comparando o início do ensino de inglês no Brasil para a atualidade, Século XXI, pode-se perceber que as dificuldades e a forma de ensino de língua inglesa não tiveram tantas modificações de como era no século XIX.
O cenário de ensino de língua inglesa tem se modificado com o passar dos tempos. Ao ser necessário o domínio do Inglês, idioma considerado universal, conforme afirmam Tutida e Tonelli (2014, p. 745). Primeiramente adultos procuraram escolas de idiomas para conseguirem uma vaga no mercado de trabalho com esse diferencial. Após algum tempo, os pais passaram procurar um curso de idioma para os filhos adolescentes e, atualmente, na nova conjuntura são os pais que procuram cursos de idiomas cada vez mais cedo para seus filhos com 2, 3, 4 e 5 anos, seguindo uma tendência abraçada pelas escolas regulares tanto públicas quanto privadas que passaram a ofertar o ensino de língua inglesa a partir da Educação Infantil, e Ensino Fundamental I, mesmo sem a obrigatoriedade em lei para poder se enquadrar no quesito de formação integral do aluno como cidadão do mundo.

O aumento pelo interesse do domínio da língua inglesa pode se explicar nas palavras de Moura (2009, p. 19):

“A escola não está descolada da realidade social. Ela recebe influências e também influencia a sociedade. As mudanças sociais, econômicas e científicas têm um impacto na escola, que se reorganiza em função dessas influências e exerce influência na sociedade".

Ao enxergar esse novo contexto, Educação Infantil, questiona-se quem são as pessoas que vão trabalhar com esse público visto que as matrizes curriculares dos Cursos de Letras ainda não abordam em sua grade, disciplinas tanto práticas quanto teóricas a respeito deste tema. Por este motivo notase uma lacuna na formação inicial do professor que vai atuar com os alunos denominados crianças. ${ }^{3}$

Um ponto curioso relacionado com as Diretrizes Curriculares Nacionais é por exemplo, a DCN CNE/ CEB 7/2010, parágrafo primeiro que diz: "Nas escolas que optarem por incluir Língua Estrangeira

\footnotetext{
${ }^{3}$ Segundo o Estatuto da Criança e do Adolescente, Lei 8069/90 de 13 de julho de 1990, considera-se criança, a pessoa até doze anos de idade incompletos.
} 
nos anos iniciais do Ensino Fundamental, o professor deverá ter licenciatura específica no componente curricular" CONSELHO NACIONAL DE EDUCAÇÃO, 2010, p. 9). Segundo Tutida e Tonelli (2014), supõe-se que o professor que vai trabalhar com essa disciplina deve ser graduado em um Curso de Letras com formação específica nessa língua estrangeira. Porém, como o Curso de Letras não tem foco para ensino de Inglês para crianças, quem forma o professor para ensinar inglês para crianças dos anos iniciais de Educação Infantil e Ensino Fundamental I? Seria o Curso de Pedagogia?

Segundo as Diretrizes Curriculares Nacionais para o Curso de Graduação em Pedagogia nos artigos $4^{\circ}$ e $5^{\circ}$ de 2006, o curso oferece formação sobre desenvolvimento infantil e aprendizagem; porém não oferecem formação em língua estrangeira por este não ser o foco do Curso sendo que o egresso deverá estar apto a ensinar Língua Portuguesa, Matemática, Ciências, História, Geografia, Artes, Educação Física, de forma interdisciplinar e adequada às diferentes fases do desenvolvimento humano. Já os Cursos de Letras Português- Inglês se preocupam com a formação de professores de línguas materna e/ou estrangeiras, mas o foco é nas teorias voltadas aos alunos a partir do $6^{\circ}$ ano conforme a resolução CNE/CP n 2 de 19/02/2002 que institui as Diretrizes Curriculares Nacionais, artigo $6^{\circ}$ o qual mostra que os estágios tanto de observação, regência e participação são feitos no Ensino Fundamental II e Ensino Médio. (CONSELHO NACIONAL DE EDUCAÇÃO, 2002, 2006).

As grades curriculares dos Cursos de Letras ainda não avançaram como os currículos das escolas regulares, principalmente privadas, já fizeram. É possível perceber uma distância entre o que a escola deseja do professor e os insumos que ele recebe na faculdade.

De acordo com o Parecer CNE/CP n²/2015 e levando em consideração a complexidade da educação de modo geral, espera-se que o professor tenha a concepção sobre conhecimento de educação (no caso deste artigo, o conhecimento sobre o aluno criança, como aspectos de desenvolvimento da linguagem, aprendizagem e características das fases de cada idade), valorização da experiência extraescolar (aquilo que o professor aprende na prática e seu conhecimento geral do mundo) e o pluralismo de ideias e de concepções pedagógicas (estar aberto à novas possibilidades de ensino, pois é o que está acontecendo hoje em dia na educação, o redimensionamento do professor). Ademais, levando em consideração a proposta de multiletramento parecer acima supracitado, uma língua estrangeira é parte constitutiva da pluralidade cultural. (CONSELHO NACIONAL DE EDUCAÇÃO, 2015).

A oferta de ensino de língua inglesa a partir da educação infantil exige novas posturas e dinâmicas na formação inicial de professores de língua inglesa. De acordo com Tonelli, Ferreira e Belo-Cordeiro (2017) é necessário analisar o perfil e a realidade dos professores e das escolas para aproximar o curso de formação inicial ao campo de atuação desses professores.

Neste sentido, o presente artigo tem por objetivo apresentar uma análise de currículos de dois Cursos de Letras Português-Inglês de Instituições Federais de Ensino localizadas no Sudoeste do Paraná, procurando identificar, caso possível, espaços que possam comtemplar o ensino-aprendizagem de Inglês para a educação infantil.

\section{Fundamentação Teórica}

Ao tratar de uma lacuna na formação inicial e continuada dos acadêmicos do curso de Letras Português Inglês é necessário fazer uma análise das leis que regulamentam o Ensino de Inglês no Brasil e conhecer um pouco a história das Universidades as quais farão parte desta pesquisa. Nesta seção também será apresentado um panorama das escolas das duas cidades analisadas, considerando o número de escolas que ofertam o Ensino de Inglês na Educação Infantil e Ensino Fundamental I. 


\section{Leis que regulamentam o ensino de Inglês}

Em 1961, a Lei de Diretrizes e Bases (LDB) muda o currículo de ensino de "ginásio" e "científico" para 1o e 2 o graus. Essa lei estabelece que o ensino de uma língua estrangeira (LE) moderna é o único do núcleo comum a ter obrigatoriedade apenas parcial para o 1 o grau, mas recomenda a inclusão da língua "onde e quando tenha o estabelecimento condições de ministrá-la com eficiência" (CHAGAS, 1980 apud CHAVES, 2004, p. 8).

Dez anos depois da primeira LDB, foi publicada a LDB de 1971, a Lei 5692. Esta lei reduz o ensino de 12 para 11 anos, sendo oito anos de $1^{\circ}$ grau e três de $2^{\circ}$ grau. A redução da escolaridade e o novo foco profissionalizante provocaram uma redução drástica na carga horária de LE, “agravada ainda por um parecer posterior do Conselho Federal de que a língua estrangeira seria 'dada por acréscimo' dentro das condições de cada estabelecimento" (LEFFA, 1999, p. 10). Como consequência desta situação, muitas escolas tiraram a LE do $1^{\circ}$ grau e reduziram a carga horária do $2^{\circ}$ grau para até 1 hora semanal.

A LDB de 1996 substitui o $1^{\circ}$ e $2^{\circ}$ graus por Ensino Fundamental e Ensino Médio e deixa bem claro a necessidade de uma LE no Ensino Fundamental, cuja escolha da língua ficaria a cargo da comunidade escolar. Quanto ao Ensino Médio, a lei estabelece a obrigatoriedade de uma LE moderna, havendo a possibilidade de uma segunda língua optativa, de acordo com as disponibilidades da instituição. (BRASIL, 1996).

De acordo com os Parâmetros Curriculares Nacionais (PCN) de 1999 que complementam a nova LDB,

[...] no âmbito da LDB, as Línguas Estrangeiras Modernas recuperam, de alguma forma, a importância que durante muito tempo lhes foi negada", já que elas "assumem a condição de serem parte indissolúvel do conjunto de conhecimentos essenciais que permitem ao estudante aproximar-se de várias culturas $\mathrm{e}$, consequentemente, propiciam sua integração num mundo globalizado (BRASIL, 1999).
Por sua vez, os PCN não propõem uma metodologia específica para o ensino de línguas, mas sugerem uma abordagem sócio-interacional, com ênfase no desenvolvimento da leitura. De acordo com o documento a leitura atende "[...] as necessidades da educação formal, e, por outro lado, é a habilidade que o aluno pode usar em seu próprio contexto social imediato. Além disso, a aprendizagem de leitura em LE pode ajudar o desenvolvimento integral do letramento do aluno" (BRASIL, 1999).

Essa abordagem do ensino da LE, somados a vários outros fatores, tais como a falta de professores qualificados e que realmente dominem a língua, os materiais didáticos não apropriados (ou até mesmo inexistentes no caso de algumas escolas públicas), metodologia antiga e inadequada, turmas muito grandes dificultam o aprendizado da LE, tanto na escola pública quanto na particular. Infelizmente, apesar das leis e reformas, o ensino de Inglês nas redes de escolas de Ensino Fundamental/Médio até hoje em dia "parece ter ficado encalhado no método de tradução e gramática do início do século" (SCHÜTZ, 2002).

Como o próprio nome sugere, os PCN - LEM (BRASIL, 1999) constitui uma das importantes ferramentas de trabalho que deve auxiliar o professor na sua formação acadêmica, nas atividades profissionais e/ou pessoais. O documento foi criado com a intenção de nortear o ensino de língua estrangeira, porém, os professores não foram devidamente orientados para a melhor maneira de utilizá-lo. No caso do ensino de Inglês para crianças, sequer existe um documento oficial para nortear o ensino.

A Base Nacional Comum Curricular - BNCC (CONSELHO NACIONAL DE EDUCAÇÃO, 2017), é um documento que define os conjuntos de conhecimentos a serem aprendidos em todos os níveis de educação do país. Neste conjunto, elege a língua inglesa não mais como língua do falante nativo, mas como língua franca, ou seja: a língua 
que é falada em diferentes contextos mundiais por falantes de outras línguas que optam por falar o inglês como a língua da comunicação. Não se trata de uma variante da língua inglesa, mas de uma língua de comunicação e interação, conforme Seidlhofer (2011, p. 7) "qualquer uso do inglês entre falantes de diferentes línguas maternas para quem ele é o meio de comunicação escolhido, e frequentemente, a única opção".

Conforme Gimenez et al. (2015), estudos em contexto brasileiro têm sido realizados seguindo uma perspectiva de que o inglês é uma língua franca de alcance global (e.g. BORDINI; GIMENEZ, 2014; CALVO; EL KADRI, 2010, 2013; EL KADRI; GIMENEZ, 2013; SIQUEIRA, 2010, dentre outros). Neste sentido, a aprendizagem de inglês é crucial, uma vez que pode contribuir para que o aprendiz se desenvolva interculturalmente e melhor entenda o mundo em que vive.

No entanto, em sua terceira revisão, a BNCC contempla a disciplina Língua Inglesa compulsoriamente a partir do $6^{\circ}$ ano do Ensino Fundamental II. Desta forma, novamente nos perguntamos a quem compete a formação de professores de Inglês para a Educação Infantil e Ensino Fundamental I?

No próximo tópico, procuraremos analisar 2 currículos de Cursos de Licenciatura em Letras de duas instituições de Ensino Superior e desta forma tentar encontrar espaços para a discussão do processo de ensino-aprendizagem de inglês para crianças.

\section{Histórico dos cursos de Letras nas duas instituições participantes}

Instituição1: Em 01 de julho de 1967, através do Decreto Federal n 63.583foi aprovada a FAFI Faculdade de Filosofia, Ciência e Letras de Palmas - Paraná, cujas aulas tiveram início em março de 1969. Em 1979, com o aumento na demanda de cursos, o campus passou a atender pelo nome FAFI/
FACEPAL-Faculdades Reunidas de Administração, Ciências Contábeis e Econômicas de Palmas, abrangendo todo o Sudoeste do Paraná, Oeste de Santa Catarina e Rio Grande do Sul. No ano de 2001 criou-se a FACIPAL - Faculdades Integradas Católicas de Palmas e em 2008 tornou-se UNICS - Centro Universitário Católico do Sudoeste do Paraná até chegar em 2010 com a instalação oficial do IFPR - Instituto Federal do Paraná, tornando-se o maior complexo universitário do Instituto Federal no Brasil e oportunizando à população Educação Superior Federal.

De acordo com Nazaro (2010) ao entregar a Universidade para o Instituto Federal, o UNICS somava em números: 02 campi com cerca de 2.000 alunos(considerando Pós-Graduação); 200 professores; 150 funcionários; 17 Cursos de Graduação; 28 cursos de Pós graduação (lato sensu); 14 Projetos de Pesquisa; dezenas de Programas e Eventos de Extensão Universitária; 02 Cursos Técnicos Profissionalizantes; 36 mil metros de área construída; biblioteca com mais de 100.000 volumes (a maior da região Sudoeste PR); 110 salas de aula; 18 laboratórios (Química, Física, Biologia, Informática, Línguas, Engenharia Civil, Pedagogia etc); 02 escritórios modelo (Contábeis e Direito); 01 Empresa Júnior (Administração); 02 auditórios com 1200 lugares; 01 Centro de Documentação e Pesquisa; 02 quadras poliesportivas; 01 piscina térmica coberta; 01 campo de futebol oficial; 01 pista de atletismo; 01 estúdio de gravação para TV.

O Curso de Letras está imbricado com a história da Instituição, pois é o único que se manteve desde o início em 1969 até os dias atuais (2017) e seu histórico é extenso e muito significativo para a formação de professores de Letras no Sudoeste do Paraná.

O Curso de Letras iniciou suas atividades com a autorização da antiga Faculdade de Filosofia, Ciências e Letras de Palmas - FAFI, pelo Decreto Federal $n^{\circ}$. 63.583/68, ministrando a habilitação de Português/Francês e respectivas literaturas. 
Pelo Decreto Federal n ${ }^{\circ}$. 74.352, de 01/08/1974, foi autorizada a habilitação de Português/Inglês e respectivas literaturas. Em 1979, foi autorizada pelo Decreto $n^{\circ} .83 .472$ a habilitação de Português e Literaturas da Língua Portuguesa. Em 1998, agregou a habilitação de Português/Espanhol e respectivas literaturas, reconhecida pela Portaria $\mathrm{n}^{\mathrm{o}}$. 1.282, de 17/05/2004. A partir de 2004, entrou em vigor a nova matriz curricular para os Cursos de Letras Português/Inglês, Letras Português/ Espanhol e Letras Português, publicada no D.O.U. $n^{\circ}$. 210, fls. 104, em 29 de outubro de 2003. O Projeto Pedagógico do Curso de Letras do UNICS foi, então, reformulado. A carga horária dos cursos com habilitação em Línguas Estrangeiras seria cumprida em 07(sete) semestres, enquanto que a carga horária do Curso de Letras Português passou a ser integralizada em um mínimo de 06(seis) semestres. Em 2004, o UNICS optou por ofertar somente Letras Inglês e Letras Espanhol. Em 2007, ofertou apenas Letras Inglês. Em 2008, de acordo com a reestruturação curricular da instituição, a matriz curricular do curso de Letras Português/ Inglês e respectivas literaturas foi reformulada. Em 2010, com a federalização da instituição, o Centro Universitário Católico do Sudoeste do Paraná deixou de existir e o Instituto Federal do Paraná assumiu seus alunos, pelo processo de transferência. Em 2011, não houve ingressantes, procedeu-se a reestruturação do Curso de Letras, que resultou em uma nova proposta de matriz curricular, elaboração de um novo projeto pedagógico, para a oferta de uma nova turma de acadêmicos ingressantes em 2012, com 40 vagas noturnas (estágios diurnos), licenciatura plena em Letras, com duas habilitações: Português e Inglês e suas respectivas literaturas.

Instituição 2: De acordo com a página ${ }^{4}$ on line da UTFPR, Câmpus Pato Branco, em 1990, o Governo Federal, através do Programa de Expansão e Melhoria do Ensino Técnico fez com que o Centro
Federal de Educação Tecnológica - CEFET- PR -se expandisse para o interior do Paraná, onde foram implantadas cinco unidades, dentre as quais, a Unidade de Pato Branco. As negociações iniciaram ainda no ano de 1987 e em 1989, a Prefeitura Municipal de Pato Branco, liderada pelo Senhor Clóvis Santo Padoan, repassou ao CEFET - PR a área anexa à Fundação de Ensino Superior de Pato Branco (FUNESP) e ainda nesse ano se iniciaram as obras físicas das futuras instalações da Unidade de Pato Branco do CEFET - PR.

As primeiras aulas foram ministradas dia 15 de março de 1993 e a aula inaugural realizada no dia 29 de março. Entretanto, a cerimônia oficial de inauguração da Unidade de Ensino de Pato Branco aconteceu no dia 17 de abril do mesmo ano. Nessa época, a Unidade contava com 22 professores, 57 técnicos administrativos e 442 alunos. Ofertava 02 cursos (Técnico em Edificações e Eletrônica), possuía 02 laboratórios e um acervo de 411 títulos na biblioteca.

Em 2005, ocorre a mudança mais marcante desse período: a transformação do CEFET/PR em Universidade Tecnológica Federal do Paraná UTFPR -, a primeira universidade tecnológica do Brasil, que após sete anos de preparo e o aval do governo federal, o projeto de transformação da Instituição em Universidade Tecnológica tornou-se lei no dia 7 de outubro de 2005 .

A oferta do Curso de Licenciatura em Letras na cidade de Pato Branco - Paraná se deu inicialmente no ano de 1986, ofertado pela FUNESP com autorização do Decreto Presidencial n 90.775, de 28/12/85, e suas atividades foram regularmente desenvolvidas até o ano de 1993 quando iniciou-se o processo de incorporação da FUNESP à unidade de Pato Branco do CEFET - PR. Em setembro desse mesmo ano, em reunião com a Congregação dos Professores, considerou-se inviável a continuidade

\footnotetext{
${ }^{4}$ Disponível em: http://www.utfpr.edu.br/patobranco/estrutura-universitaria/diretorias/dirgrad/cursos/colet/documentos/normativas/projeto-pedagogico-do-curso-de-licenciatura-em-letras-portugues-ingles-da-utfpr
} 
do Curso de Licenciatura em Letras, tendo sido suspenso seu vestibular pelo Parecer de no 325/93. No ano de 1996, aconteceu a formação dos últimos profissionais na área de Licenciatura em Letras Português-Inglês com certificados do CEFET $\mathrm{PR}$, pois as turmas que estavam em andamento na FUNESP, concluíram o curso com os professores concursados do CEFET - PATO BRANCO.

A suspensão desse Curso criou uma demanda por um novo Curso Superior de Licenciatura em Letras em uma instituição pública, visto que o públicoalvo eram pessoas do Oeste e o Sudoeste do Paraná, além das regiões do Oeste e extremo Oeste de Santa Catarina e que outro curso nesta área, disponível na região encontrava-se à $96 \mathrm{Km}$ de distância, na cidade de Palmas - PR e esta era uma instituição de ensino privada e por este motivo era de suma importância a reabertura deste curso na cidade.

Desde então, professores preocupados com a formação de profissionais nesta área, trabalharam pela reabertura do referido curso, conquistando-a no segundo semestre de 2008 Nesse período UTFPR passou a oferecer o curso de Licenciatura em Letras Português-Inglês, no período noturno, com o ingresso de 44 alunos por semestre.

\section{O ensino de inglês para crianças}

O desafio para quem trabalha inglês com crianças é enorme. Cameron (2001) afirma que diferentemente do que muitos pensavam e ainda pensam, trabalhar com crianças não é uma tarefa simples. Trata-se de uma atividade complexa que exige muita preparação do professor. No entanto, ainda hoje é possível ouvir de professores egressos que tendo um "conhecimentozinho" assim básico, os básico dos básicos" dá para trabalhar nas séries iniciais. (CARVALHO, 2013, p. 164).

Segundo Magalhães (2013, p. 248-249), o professor de Língua Inglesa para Crianças (LIC) deve conhecer as características do desenvolvimento físico, emocional e cognitivo das diferentes faixas etárias; deve ter prazer de ensiná-las; deve ter domínio do idioma e conhecimento teórico, além de doses generosas de paciência, afetividade, criatividade e dinamismo.

A demanda por professores para atuar com crianças tem aumentado, enquanto que a formação para este profissional ainda não é suficientemente oferecida em cursos de formação inicial e/ou continuada. Neste sentido, já não é sem tempo que as universidades incluam em seus currículos disciplinas que tratem do ensino-aprendizagem de LIC consideramos citar, neste trabalho, duas pesquisas científicas devido a importância de seus resultados. A primeira delas é a pesquisa realizada por Tonelli e Cristovão (2010), que ofertaram aos alunos de uma universidade pública do Paraná uma disciplina eletiva intitulada "Ensino de Língua Inglesa para Crianças", com o intuito de observar a percepção dos alunos em relação a LIC. Os resultados da pesquisa apontam que $100 \%$ dos alunos afirmam ser muito importante a inserção de uma disciplina voltada para o ensino de inglês para crianças, visto que vários já estavam atuando com esse público ou vendo o crescimento desta área de trabalho, outros estavam se preparando para atuar neste mercado e muitas questões teóricas e práticas apareciam frequentemente.

Outra pesquisa importante foi a realizada por Tonelli, Ferreira e Belo-Cordeiro (2017), na qual egressos dos últimos 7 anos do Curso de Licenciatura em Letras Português-Inglês de uma universidade estadual do Paraná responderam a um questionário on line, cujos resultados foram: a) $37 \%$ dos respondentes afirmaram estar atuando com o público infantil; b) $100 \%$ dos participantes foram unânimes ao afirmar que o referido curso não prepara para atuar na Educação Infantil e Fundamental I; e c) $100 \%$ indicaram que a disciplina Ensino de Inglês para Crianças deveria constar no rol de disciplinas do curso. 
Segundo Santos (2011), as instituições responsáveis pela formação inicial têm papel decisivo na promoção do conhecimento profissional e dos aspectos da profissão docente, comprometendo-se com o contexto e a cultura em que esta se desenvolve.

\section{Aspectos metodológicos}

Com o objetivo de analisar como as Universidades do Sudoeste do Paraná têm se adaptado para formar professores de Inglês aptos a atuar junto ao público infantil, foi realizado um levantamento dos currículos dos Cursos de Licenciatura em Letras Português/Inglês de duas Universidades Públicas da região. É importante lembrar que não temos o objetivo de criticar as referidas universidades, mas sim o de contribuir para uma melhor formação inicial e identificar possíveis ações para a formação continuada de professores de Inglês.

A pesquisa a ser aqui apresentada é de natureza qualitativa e exploratória, cujo objetivo principal é apresentar uma análise de currículo de dois Cursos de Letras Português - Inglês de Instituições Federais de ensino localizadas no sudoeste do Paraná. Para Goldenberg (1997, p. 34), a preocupação principal da pesquisa qualitativa é o aprofundamento da compreensão de um grupo social, organização, etc. Já a pesquisa exploratória visa proporcionar maior familiaridade com o problema com vistas a torna-lo mais explícito ou a construir hipóteses (GIL, 2007).

Para tal, nos dias 18 e 19 de maio de 2018, pesquisamos nos sites $^{5}$ das universidades selecionadas os currículos dos dois referidos cursos. Também acessamos os sites das cidades, nas quais se localizam os Cursos de Letras, para um levantamento sobre o número de escolas ${ }^{6}$ que ofertam Educação Infantil e Ensino Fundamental I. Logo após foi entrado em contato, via telefone, com cada escola para perguntar a respeito da oferta do ensino do idioma ou não. De posse desses dados, procedemos a análise interpretativa a seguir.

\section{Análise e Discussão de Dados}

Ao fazer levantamento das escolas de Educação Infantil e Ensino Fundamental nas cidades de Pato Branco e Palmas/ PR, foi possível perceber que o aumento de escolas que ofertam o ensino de Inglês desde as séries iniciais têm crescido, bem como a demanda por professores que atuam junto a esse público.

Segundo o censo ${ }^{7}$ 2016, a cidade de Pato Branco tem uma população estimada em 79.869 habitantes e nela há 76 escolas, entre públicas (municipais, estaduais, federal) e privadas. Também de acordo com o censo ${ }^{8}$ 2016, a cidade de Palmas tem uma população estimada em 48.339 habitantes e possui 39 escolas, entre públicas (municipais, estaduais, federal) e privadas.

Após fazer o levantamento do número de escolas de cada cidade foram levantados os dados sobre quantas delas ofertam Educação Infantil e Ensino Fundamental I e dentre essas escolas quantas delas ofertam o Ensino de Língua Inglesa e assim chegamos ao gráfico abaixo:

\footnotetext{
${ }^{5}$ Disponível em: http://palmas.ifpr.edu.br/graduacao/letras-portuguesingles/matriz-curricular/ e http://www.utfpr.edu.br/estrutura-universitaria/pro-reitorias/prograd/catalogo-de-cursos-da-utfpr/pato-branco/licenciatura-em-letras-portugues-ingles\#Disciplinas

${ }^{6}$ Disponível em: http://www.escolas.inf.br/pr/palmas e http://www.escolas.inf.br/pr/pato-branco

${ }^{7}$ Disponível em: http://cidades.ibge.gov.br/xtras/perfil.php?codmun=411850

${ }^{8}$ Disponível em: http://cidades.ibge.gov.br/xtras/perfil.php?lang=\&codmun=411760\&search=parana|palmas
} 
Gráfico 1 - Número de escolas que ofertam disciplina de Inglês

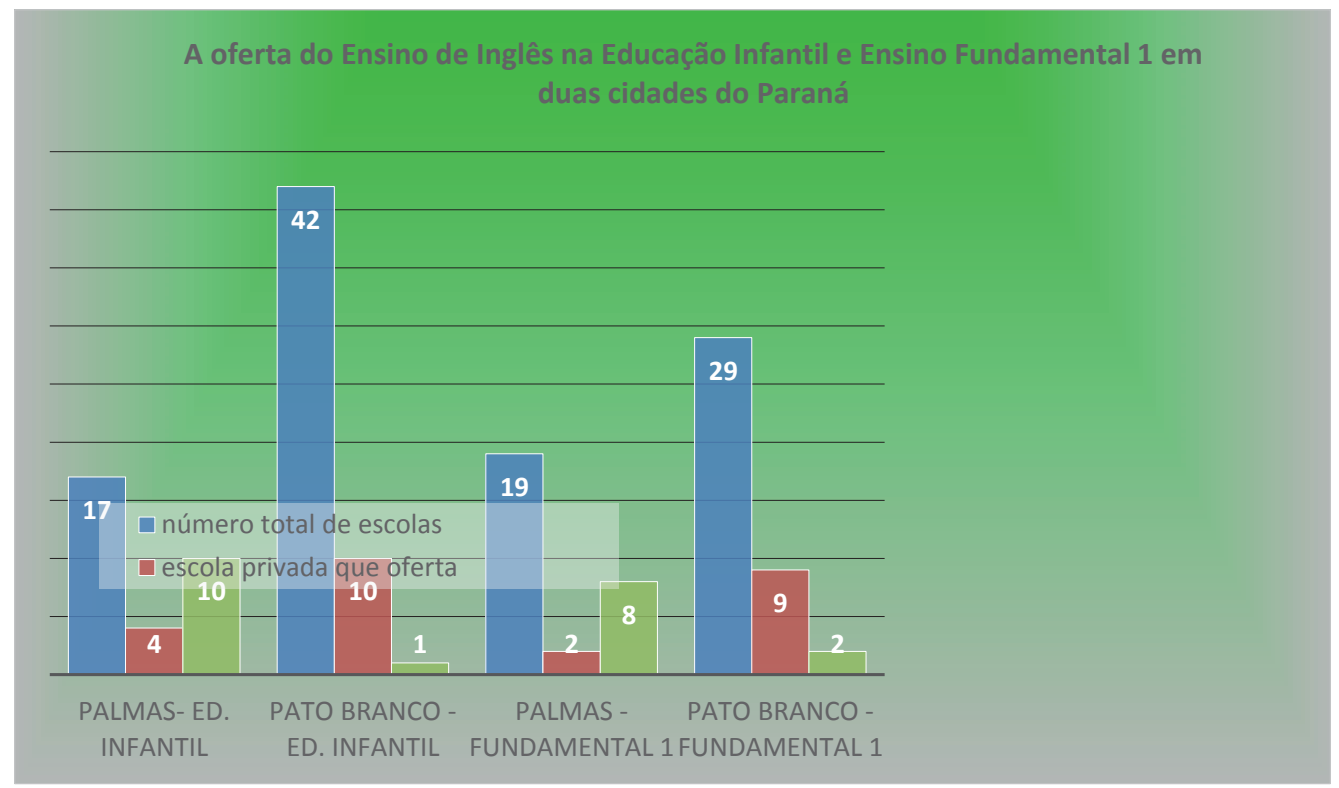

Fonte: Dados da pesquisa, 2018

Quando tratamos das escolas de Educação Infantil, 26\% das escolas de Pato Branco já ofertam aulas de Inglês, sendo $90 \%$ escolas da rede privada. Na cidade de Palmas, mesmo sendo uma cidade consideravelmente menor, $82 \%$ das escolas de Educação Infantil oferecem aulas de Inglês sendo $28,58 \%$ escolas da rede particular, $64,28 \%$ da rede municipal (CMEIS) e 7,14\% da rede estadual.

Das escolas que oferecem Ensino Fundamental 1 na cidade de Pato Branco, 37\% têm a disciplina de Língua Inglesa nos currículos, sendo $81,81 \%$ da rede privada e $18,18 \%$ da rede municipal. Já na cidade de Palmas, 53\% das escolas de Ensino Fundamental I ensinam Inglês, num percentual de $20 \%$ advinda da rede privada, $70 \%$ da rede municipal e $10 \%$ da rede estadual.

Ao analisar os currículos das Instituições 1 e 2, seja Universidade 1 e Universidade 2, foi possível perceber que ambas as possuem 8 períodos, correspondentes a 8 semestres, ou seja, o acadêmico estuda o mínimo de 4 anos para conseguir a certificação. Em uma primeira observação já foi possível verificar que nenhuma das instituições têm uma disciplina específica para trabalhar o Ensino de Inglês para Crianças.

Ao analisar a descrição do curso no site $e^{9}$ da Instituição 1 a respeito da área em que o aluno pode atuar, é possível perceber a lacuna existente para a formação do professor que vai trabalhar na Educação Infantil e Ensino Fundamental 1:

O Curso Superior de Licenciatura em Letras Português - Inglês, objetiva formar profissionais para atuarem como docentes de Português e/ou Inglês na Educação Básica com a possibilidade de optar por outras áreas profissionais. O campo de trabalho para o profissional Licenciado é vasto e promissor, pois o egresso poderá atuar como: professor de Português e/ou Inglês no Ensino Fundamental e no Ensino Médio ${ }^{10}$; professor de Português e/ou Inglês no Ensino Superior; professor de Português para falantes de outras línguas; professor em cursos de capacitação que visam ao aprimoramento do uso da língua materna e/ou da língua inglesa; assessor técnico; editor e intérprete da língua inglesa; revisor e redator de textos; roteirista e assessor cultural.

\footnotetext{
${ }_{9}^{9}$ Disponível em: http://www.utfpr.edu.br/estrutura-universitaria/pro-reitorias/prograd/catalogo-de-cursos-da-utfpr/pato-branco/licenciatura-em-letras-portugues-ingles

${ }^{10}$ Grifo da autora.
} 
$\mathrm{Na}$ Universidade 1 percebem-se as seguintes disciplinas ${ }^{11}$ voltadas para o Inglês:

Tabela 1 - Disciplinas relacionadas ao Inglês na Universidade 1

\begin{tabular}{cccc}
\hline $1^{\circ}$ Período & Inglês Báscio & & \\
\hline $2^{\circ}$ Período & Inglês Báscio II & & \\
\hline $3^{\circ}$ Período & Inglês Pré Intermediário & & \\
\hline $4^{\circ}$ Período & Inglês Pré Intermediário II & & \\
\hline $5^{\circ}$ Período & Inglês Intermediário I & Estágio & \\
\hline $6^{\circ}$ Período & Inglês Intermediário II & Estágio & Estágio \\
\hline $7^{\circ}$ Período & Inglês Intermediário II & Literatura de Língua Inglesa & \\
\hline $8^{\circ}$ Período & Inglês Avançado II & Literatura de Língua Inglesa & \\
\hline
\end{tabular}

Fonte: Dados da pesquisa, 2018.

Seguem disciplinas ${ }^{12}$ ofertadas pela Universidade 2:

Tabela 2 - Disciplinas relacionadas ao Inglês na Universidade 2

\begin{tabular}{llll}
\hline $1^{\circ}$ Período & Língua Inglesa I & & \\
\hline $2^{\circ}$ Período & Língua Inglesa II & & \\
\hline $3^{\circ}$ Período & Língua Inglesa III & & \\
\hline $4^{\circ}$ Período & Língua Inglesa IV & & \\
\hline $5^{\circ}$ Período & $\begin{array}{l}\text { Prática de ensino de Língua } \\
\text { Inglesa }\end{array}$ & Língua Inglesa V & $\begin{array}{l}\text { Literaturas de Língua Inglesa: Contos e } \\
\text { Romances }\end{array}$ \\
\hline $6^{\circ}$ Período & Estágio em Língua Inglesa I & Língua Inglesa VI & Literaturas de Língua Inglesa: Poesia \\
\hline $7^{\circ}$ Período & Estágio em Língua Inglesa II & Língua Inglesa VII & Literaturas de Língua Inglesa: Teatro \\
\hline $8^{\circ}$ Período & Docência em Língua Inglesa & Língua Inglesa VIII & \\
\hline
\end{tabular}

Fonte: Dados da pesquisa, 2018.

Ao analisar as ementas ${ }^{13}$ das disciplinas voltadas ao Inglês é possível perceber que essas disciplinas buscam a compreensão e produção de textos, assim como compreensão oral e escrita nos níveis básico, intermediário e avançado em ambas as universidades. As disciplinas de Inglês contempladas nas grades curriculares dos cursos de Letras têm como foco principal o ensino do idioma, portanto nas estruturas básicas: vocabulário e gramática. $\mathrm{O}$ inglês nos currículos das universidades investigadas aparece com o foco de desenvolver as quatro habilidades comunicativas (ler, escrever, falar e ouvir) no acadêmico e não com estratégias e ensino nos diferentes níveis. Nas duas universidades há disciplinas de estágios, em que os acadêmicos vão para sala de aula, porém apenas a partir o Ensino Fundamental II.

${ }^{11}$ Disponível em: http://palmas.ifpr.edu.br/wp-content/uploads/2017/05/Letras-Portugu\%C3\%AAs-Ingl\%C3\%AAs.pdf

${ }_{12}$ Disponível em: http://www.utfpr.edu.br/patobranco/estrutura-universitaria/diretorias/dirgrad/cursos/colet/disciplinas/matrizcurricular-596

${ }^{13}$ Disponível em: http://palmas.ifpr.edu.br/wp-content/uploads/2018/11/LETRAS.pdf 
Segundo Paiva (2009, p. 33), a língua deve fazer sentido para o aprendiz em vez de ser apenas um conjunto de estruturas gramaticais. E hoje, as escolas deixam claro que é preciso trabalhar léxico e sintaxe de forma contextualizada para que o aluno sinta a língua viva e se sinta com liberdade para utilizá-la mais diversas situações de comunicação e interação sem foco em tradução e gramática como era no século XIX (LEFFA, 1999), porém, a experiência que o aluno-professor teve durante a formação inicial foi focado em regras gramaticais e tradução, com poucas abordagens na oralidade. Conforme Krashen (1985), o acadêmico sai da universidade dominando as regras (espera-se), mas na hora da conversação ele trava e sente dificuldade em se comunicar. Já em sala de aula, enquanto professor, ele sentirá dificuldades em contextualizar o conteúdo já que pouco o fez durante sua formação inicial.

Em uma pesquisa realizada por Carvalho (2013) com egressos de um Curso de Letras Português/ Inglês, eles se mostraram angustiados ao entrarem em sala de aula e conseguirem se desvincular do ensino de gramática, já que eles têm ensinado o idioma de acordo com aquilo que aprenderam durante a faculdade.

Nos dois currículos foi possível verificar que gêneros da literatura estrangeira são apresentados aos acadêmicos, porém nenhum gênero infantil é abordado. Segundo Willians e Burden (1997), é muito importante utilizar dramatizações, músicas e contação de histórias na hora de ensinar um idioma para as crianças, visto que isso acontece muito em sua rotina na língua materna. Se o professor conseguir utilizar de forma correta, interpretando, fazendo as vozes, usando fantasias, a criança se interessará mais pelo idioma.

No terceiro período da Universidade 1 e no segundo período da Universidade 2, os acadêmicos têm a disciplina de Psicologia da Educação na qual são abordados temas como desenvolvimento e aprendizagem, desenvolvimento neuropsicológico e motor, baseados em autores como Jean Piaget
(1986) e Vygotski (2001). É uma disciplina importante na qual o acadêmico tem a possibilidade de compreender, mesmo que de forma superficial, como acontece o desenvolvimento da criança, porém talvez ele não consiga construir sentido dos textos ou realizar uma transposição didática adequada quando estiver em sala de aula, uma vez que não vivenciou práticas pedagógicas pertinentes ao público infantil, ou seja os conteúdos teóricos vistos na universidade não condizem com a prática pedagógica de professor de Ensinos Fundamental II ou Médio. O professor de LIC deve exercer sua profissão com bom arcabouço teórico, mas como, nos currículos de letras não há disciplinas teóricas específicas com práticas específicas para criança, o futuro professor de Inglês iniciará sua trajetória profissional sem conhecimento teórico-prático suficiente para ser bem sucedido. Para Santos (2011), a ausência de formação adequada, pode levar o futuro professor a uma prática sem sentido, que prejudica o desenvolvimento da disciplina Inglês na Educação Básica, chegando a desmotivar os alunos.

No $4^{\circ}$ período da Universidade 1 , os alunos têm a disciplina de Psicolinguística. Nela, a ementa refere-se à aquisição de língua materna e línguas estrangeiras, mas com foco principal no ensino de Português nos anos iniciais do Ensino Fundamental. Novamente, este currículo se torna inadequado para preparar o professor de Línguas Estrangeiras.

Tonelli e Cristovão (2010, p. 68) afirmam que o professor que atua com LIC deve dominar a língua a ser ensinada/aprendida, ou seja deve ter domínio da dimensão técnica ou técnico-científica que unida às práticas de ensino e outros saberes contribuem para uma prática pedagógica efetiva. É importante que o aluno consiga ter proficiência da língua, visto que hoje os alunos que encontramos dentro das escolas já têm um certo entendimento da língua devido ao contato com o Inglês através de jogos, desenhos, músicas etc. Observando os currículos investigados percebe-se que ambos os cursos buscam preparar o acadêmico para este aspecto. 
Ademais, uma das competências mencionadas nas Diretrizes Curriculares para o Curso de Letras, Parecer CNE/CES no 492/2001 do Conselho Nacional de Educação (2001, p. 29) é o domínio dos conteúdos básicos e dos métodos e técnicas pedagógicas que permitam a transposição dos conhecimentos para os diferentes níveis de ensino. No entanto, o acadêmico que segue os currículos aqui investigados, não tem acesso aos métodos e técnicas que devem ser trabalhadas com crianças durante sua formação inicial, bem como terá contato, em seus estágios curriculares supervisionados, apenas com contextos escolares a partir do $6^{\circ}$ ano do Ensino Fundamental e no Ensino Médio, ou seja sai da universidade sem contato nenhum com o público infantil. Esse fato é muito intrigante, uma vez que sabemos, por meio de nossas experiências como professoras formadoras, que muitas vezes, quando formado, o professor recém formado consegue seu primeiro emprego justamente com público desta faixa etária.

Em se tratando dos estágios supervisionados de ambos os cursos, esses têm início no $5^{\circ}$ semestre do curso e são finalizados no $8^{\circ}$ semestre, porém, conforme já dito acima, os acadêmicos têm contato apenas com o público a partir do $6^{\circ}$ ano até o Ensino Médio conforme resolução $\mathrm{CNE} / \mathrm{CP}^{\circ} 2$ de 19/02/2002. Neste sentido, não é responsabilidade do curso de graduação preparar o acadêmico para atuar na Educação Infantil e Fundamental I. O momento dos estágios é aquele em que o acadêmico tem contato com uma sala de aula real e tem a possibilidade de conhecer pelo menos o mínimo do funcionamento de uma aula. Talvez esse contato tão breve não seja o suficiente para sanar todas as dúvidas dos futuros professores, mas eles já podem ter uma ideia de como são seus futuros alunos. Caso esses acadêmicos tivessem a oportunidade de ter preparação e fazer estágio com o público infantil também, muitos poderiam se afeiçoar com esses alunos ou ao contrário, perceber que não têm o perfil para trabalhar com crianças. Os currículos aqui analisados mostram que é possibilitado ao acadêmico o ensino e, no estágio, a aplicação de métodos e abordagens para atuar no Ensino Fundamental II e Ensino Médio apenas, e que as abordagens utilizadas com adolescentes do Ensino Médio também podem facilmente ser as mesmas utilizadas com alunos adultos, porém não se aplicam às crianças. (CONSELHO NACIONAL DE EDUCAÇÃO, 2002).

Brown (2001) enfatiza aspectos diferentes na aprendizagem de línguas por crianças e adultos como: foco de atenção, objetivos, como o aprendiz lida com regras, energia, entre tantos outros. Conforme o autor, algo que ainda desafia muito professores que atuam com crianças é que embora as crianças compartilhem características em comum, no momento de aprender, elas não aprendem de maneira uniforme e o professor deve saber lidar com essa situação.

É importante mencionar que embora o Currículo do Curso de Letras da Universidade 1 não contemple uma disciplina específica ao ensino de LIC, no planejamento da disciplina Práticas de Ensino do $8^{\circ}$ período do Curso, a partir de 2015, um tópico presente refere-se ao ensino de LIC. Dessa forma, foi possível que a primeira autora deste artigo ministrasse aulas sobre o ensino de LIC no contexto educacional brasileiro aos acadêmicos do $8^{\circ}$ período do referido curso, como parte de seu estágio de docência no Programa de Pós-Graduação em Letras, no primeiro semestre de 2017. Nessas aulas foram abordados tópicos importantes como: a) o perfil do professor que atua com crianças; b) diferenciação entre aprendiz adulto e aprendiz criança; c) fatores que interferem no ensino/ aprendizagem para crianças; d) objetivos do ensino de Inglês na infância; e) recursos a serem utilizados nas aulas. O objetivo principal era que os alunos conhecessem um pouco sobre o tema e despertasse a curiosidade de quem ainda não conhecia sobre esse público. No segundo semestre de 2017, com o objetivo de dar suporte aos acadêmicos de Letras da Instituição 1 sobre LIC, uma vez que, como já enfatizamos neste artigo a necessidade de tratar 
dessa importante temática, novamente a primeira autora deste texto, ofertou um curso de extensão intitulado: "A formação do professor que ensina Inglês para crianças". Nesse curso, 21 acadêmicos de $5^{\circ}, 6^{\circ}, 7^{\circ}$ e $8^{\circ}$ períodos se inscreveram, e dentre esses alguns acadêmicos justificaram que ainda não atuavam com crianças e gostariam de mais recursos para que quando surgisse a oportunidade eles pudessem estar melhor preparados. Alguns dos temas abordados nesse curso de extensão foram: a) sugestões de atividades práticas para trabalhar com as crianças; b) os erros mais comuns cometidos pelos professores de inglês que lecionam para crianças; c) o discurso do professor; d) o processo de aprendizagem do novo vocabulário pelas crianças; e) técnicas de ensino do significado das novas palavras; e) o lugar da gramática no ensino de línguas para crianças; f) Storytelling nas aulas: sugestões de aplicações; g) música e rotina nas aulas; h) avaliação de aprendizagem de alunos com idade de 3 a 5 anos.

Durante o curso de extensão, os acadêmicos tiveram a possibilidade de falar sobre as curiosidades e dificuldades que encontram ao atuar nesta área e tiveram a possibilidade de conhecer atividades práticas para atuar com as crianças, assim como sugestões de materiais que podem ser utilizados e produzidos para as aulas de LIC.

\section{Considerações Finais}

O crescimento da oferta de inglês nas séries iniciais no cenário educacional brasileiro tem impacto na formação do professor, visto que ele necessita de um enfoque metodológico específico para trabalhar com crianças, porém não o obtém na universidade.

É visível que há um distanciamento entre a formação inicial do professor de Inglês e a sua área de atuação dentro do contexto educacional atual que precisa de professores que atuem com crianças. A universidade oferta novos profissionais para atuação com o ensino de língua inglesa, porém sem as características exigidas pelo mercado de trabalho da educação infantil.

Após analisar as ementas e grades curriculares de dois Cursos de Licenciatura em Letras Português-Inglês, observamos que na atualidade as graduações não contemplam a formação específica para o processo de ensino-aprendizagem de LIC, considerando que uma formação docente adequada deve dar conta tanto da aquisição do idioma inglês, quanto das formas de ensiná-lo, com vistas a uma aprendizagem significativa, conforme apontam defensores de uma aprendizagem sóciointeracionista. (VYGOTSKY, 2001).

Julgamos importante repensar alguns aspectos dos Cursos de Licenciatura em Letras PortuguêsInglês ou em Letras Inglês, com o objetivo de que os professores em formação inicial tenham suporte para enfrentar um dos novos desafios da educação brasileira que é o ensino de língua inglês apara crianças assim como leis que regulamentem o ensino de línguas nas séries iniciais, minimizando, assim, as dificuldades encontradas nas práticas em sala de aula.

Há alguns anos atrás, por exemplo, as grades curriculares dos Cursos de Licenciatura tiveram que se redimensionar para atender alunos surdos. Segundo a Lei 10436 Decreto 5626, Capítulo II artigo 3, de 22 de dezembro de 2005, Libras deve ser inserida como disciplina curricular obrigatória nos cursos de formação de professores para o exercício do magistério, em nível médio e superior. No currículo da Universidade 2 é possível verificar nos primeiro e segundo períodos a presença da disciplina de Libras. Esperamos que em um futuro não muito distante possamos ver incluso nos currículos de Letras, disciplinas que abordem também o ensino de Inglês para crianças. (BRASIL, 2005).

Assim, como apresentamos acima, uma saída rápida para suprir a necessidade de formar professores que ensinem satisfatoriamente inglês para crianças, seria a oferta de cursos de extensão, nos quais acadêmicos interessados em trabalhar 
com este público possam buscar procedimentos metodológicos, sanar dúvidas e conhecer melhor o perfil das crianças, capacitando-se para atuar com maior segurança junto a este público e tornar seu aprendizado mais significativo.

Por fim, respondendo ao título dessa pesquisa, Há espaço para o ensino de Inglês para crianças no currículo de Cursos de Licenciatura em Letras Português-Inglês?, acreditamos que sim há espaço, talvez inicialmente de forma mais sutil para aos poucos ganhar espaço dentro da grade curricular, visto que a inclusão de novas disciplinas em um curso de graduação passa por estudos e processos, muitas vezes de longo período. Ainda, é importante lembrar que para que isso possa acontecer, os próprios professores formadores também precisam de formação continuada atualizada às novas demandas sociais e relevantes dentro da área educacional.

Em suma, gostaríamos de dizer que apesar do grande e relevante número de pesquisas na área de formação de professores de línguas, ou em nosso caso de professores de língua inglesa, as pesquisas sobre formação de professores em Língua Estrangeira para crianças ainda são muito tímidas. Espera-se que a realização deste trabalho contribua com os estudos desta área.

\section{Referências}

BRASIL. Decreto No 5.626, de 22 de dezembro de 2005. Regulamenta a Lei $\mathrm{n}^{\circ} 10.436$, de 24 de abril de 2002, que dispõe sobre a Língua Brasileira de Sinais - Libras, e o art. 18 da Lei ${ }^{\circ} 10.098$, de 19 de dezembro de 2000. Brasília: Presidência da República, 2005. Disponível em: http://www.planalto.gov.br/ccivil_03/_ato20042006/2005/decreto/d5626.htm. Acesso em: 2 set. 2017.

BRASIL. Lei $N^{o}$ 9.394, de 20 de dezembro de 1996. Estabelece as diretrizes e bases da educação nacional. Brasília, DF: Presidência da República, 1996. Disponível em: http://www.planalto.gov.br/ccivil_03/leis/19394. htm. Acesso em: 2 set. 2017.

BRASIL. Ministério da Educação. Secretaria de Educação Média e Tecnológica. Parâmetros curriculares nacionais, códigos e suas tecnologias: Língua estrangeira moderna. Brasília: MEC, 1999. p 49-63. Disponível em: http://www.sk.com.br/pcn.html. Acesso em: 20 maio 2017.

BROWN, D. 2001. Teaching by principles. New York: Pearson Education,

CAMERON, L. Teaching languages to young learners. Cambridge: Cambridge University Press, 2001.

CARVALHO, M. P. Gestão para o ensino-aprendizagem de Língua inglesa no Fundamental 1 em contexto de escolar pública. 2013. 220 f. Dissertação (Mestrado em Lingüística) - Pontifícia Universidade Católica de São Paulo, São Paulo, 2013.

CHAVES, C. O ensino de inglês como língua estrangeira na educação infantil: para inglês ver ou para valer? 2004. Monografia (Especialização em Educação Infantil) Pontifícia Universidade Católica do Rio de Janeiro, Rio de Janeiro, RJ, 2004.

CONSELHO NACIONAL DE EDUCAÇÃO. Parecer CNE/CES n $n^{\circ}$ 492/2001 de 3 de abril de 2001. Aprova as Diretrizes Curriculares Nacionais dos cursos de Arquivologia, Biblioteconomia, Ciências Sociais Antropologia, Ciência Política e Sociologia, Comunicação Social, Filosofia, Geografia, História, Letras, Museologia e Serviço Social. Brasília: MEC, 2001. Disponível em: http://portal.mec.gov.br/cne/arquivos/pdf/CES0492.pdf. Acesso em: 20 maio 2017.

CONSELHO NACIONAL DE EDUCAÇÃO. Resolução $C N E / C P$ 2, de 19 de fevereiro de 2002. Institui a duração e a carga horária dos cursos de licenciatura, de graduação plena, de formação de professores da Educação Básica em nível superior. Brasília: MEC/CNE, 2002. Disponível em: http://portal.mec.gov.br/cne/arquivos/ pdf/CP012002.pdf. Acesso em: 2 set. 2017.

CONSELHO NACIONAL DE EDUCAÇÃO. Resolução $C N E / C P N^{o} 1$, de 15 de maio de 2006. Institui Diretrizes Curriculares Nacionais para o Curso de Graduação em Pedagogia, licenciatura. Brasília: MEC/CNE, 2002. Disponível em: http://portal.mec.gov.br/cne/arquivos/ pdf/rcp01_06.pdf. Acesso em: 2 set. 2017.

CONSELHO NACIONAL DE EDUCAÇÃO. Resolução $C N E / C P N^{o} 2$, de 22 de dezembro de 2017. Institui e orienta a implantação da Base Nacional Comum Curricular, a ser respeitada obrigatoriamente ao longo das etapas e respectivas modalidades no âmbito da Educação Básica. Disponível em: http://basenacionalcomum. mec.gov.br/images/historico/RESOLUCAOCNE Cp222dedezembrode2017.pdf. Acesso em: 2 set. 2017.

CONSELHO NACIONAL DE EDUCAÇÃO. Resolução $\mathrm{N}^{\circ} 2$, de $1^{\circ}$ de julho de 2015. Define as Diretrizes Curriculares Nacionais para a formação inicial em nível 
superior (cursos de licenciatura, cursos de formação pedagógica para graduados e cursos de segunda licenciatura) e para a formação continuada. Brasília: MEC/CNE, 2015. Disponível em: http://portal.mec. gov.br/docman/agosto-2017-pdf/70431-res-cne-cp-00203072015-pdf/file. Acesso em: 20 maio 2017.

CONSELHO NACIONAL DE EDUCAÇÃO. Resolução $\mathrm{N}^{\circ}$ 7, de 14 de dezembro de 2010. Fixa Diretrizes Curriculares Nacionais para o Ensino Fundamental de 9 (nove) anos. Brasília, DF: CNE/CEB, 2010. Disponível em: http://portal.mec.gov.br/dmdocuments/rceb007_10. pdf. Acesso em: 20 maio 2017.

DIAS, M. Sete décadas de história: a Sociedade Brasileira de Cultura Inglesa. Rio de Janeiro: Sextante Artes, 1999.

FERNANDEZ, G. E; RINALDI, S. Formação de professores de espanhol para crianças no Brasil: alguns caminhos possíveis. Trabalhos em Linguistica Aplicada, Campinas, SP, v. 48, n. 2, p. 353-365, 2009.

GIL, A. C. Como elaborar projetos de pesquisa. 4. ed. São Paulo: Atlas, 2007.

GIMENEZ, T.; EL KADRI, M. S.; CALVO, L. C. S.; SIQUEIRA, D. S. P.; PORFIRIO, L. Inglês como língua franca: desenvolvimentos recentes. Revista Brasileira de Linguística Aplicada, Belo Horizonte, MG, v. 15, n. 3, p. 593-619, 2015.

GOLDENBERG, M. A arte de pesquisar. Rio de Janeiro: Record, 1997.

KRASHEN, S. D. Principles and practice in second Language acquisition. Rio de Janeiro, RJ: Prentice-Hall International, 1987.

LEFFA, Vilson J. O ensino das línguas estrangeiras no contexto nacional. Contexturas: Ensino Crítico de Língua Inglesa, São José do Rio Preto, SP, n. 4, p. 13-24, 1999. Disponível em: http://www.leffa.pro.br/textos/trabalhos/ oensle.pdf/. Acesso em: 20 maio 2017.

MAGALHÃES, V. B. O perfil e a formação desejáveis aos professores de língua inglesa para crianças. In: TONELLI, J. R. A.; CHAGURI, J. de P. (Org.). Ensino de língua estrangeira para crianças: o ensino e a formação em foco. Curitiba: Appris, 2013. v.2, p. 239-260

MOURA, S. A. Com quantas línguas se faz um país? Concepções e práticas de ensino em uma sala de aula na educação bilíngue. 2009. Dissertação (Mestrado em Educação) - Universidade de São Paulo, São Paulo, SP, 2009.

NAZARO. L. B. Resumo da história das Faculdades de Palmas - Unics. 2010. Disponível em: http://lucynazaro. blogspot.com.br/2010/03/historia-das-faculdades-depalmas-unics.html. Acesso em: 20 maio 2017.
NOGUEIRA, M. C. B. Ouvindo a voz do (pré)adolescente brasileiro da geração digital sobre o livro didático de inglês desenvolvido no Brasil. 2007. 182f. Dissertação (Mestrado em Letras) - Pontifícia Universidade Católica do Rio de Janeiro PUC-Rio, Rio de Janeiro, RJ, 2007.

PAIVA, V. L. M. O ensino de língua estrangeira e a questão da autonomia. In: LIMA, D. C. (ed.). Ensino $e$ aprendizagem de língua inglesa: conversa com especialistas. São Paulo: Parábola Editorial, 2009. p. 3038.

PIAGET, J. A linguagem e o pensamento da criança. Tradução de Manuel Campos. São Paulo: Martins Fontes, 1986.

SANTOS, L. I. S. Professores de língua inglesa para crianças: interface entre formação inicial e continuada, experiência e fazer pedagógico. Revista Brasileira de Linguística Aplicada: RBLA, Belo Horizonte, MG, v. 11, n. 1, p. 223-243, 2011.

SCHÜTZ, R. A evolução do aprendizado de línguas ao longo de um século. English Made in Brazil. 2002. Disponível em: http://www.sk.com.br/sk-apren.html. Acesso em: 18 maio 2017.

SEIDLHOFER, B. Understanding English as a lingua franca. Oxford: Oxford University Press, 2011.

TONELLI, J. R. A.; CRISTOVÃO, V. L. L. O papel dos cursos de Letras na formação de professores de inglês para crianças. Calidoscópio, São Leopoldo, RS, n. 1, p. 65-76, 2010.

TONELLI, J. R. A.; FERREIRA, O. H.; BELOCORDEIRO, A. Remendo novo em vestido velho: uma reflexão sobre os cursos de Letras-Inglês. REVELLI: Revista de Educação, Linguagem e Literatura, Inhumas, GO, v. 9, n. 1, p. 124-141, 2017.

TUTIDA, A. F.; TONELLI, J. R. A. Formação inicial e continuada de professores de língua inglesa para crianças: visitando o Estado do Paraná. In: SEMINÁRIO DE PESQUISA EM CIÊNCIAS HUMANAS, 9., 2014, Londrina, PR. Anais [...]. Londrina: UEL, 2014. p. 744752.

VYGOTSKY, L. S. A construção do pensamento e da linguagem. São Paulo: Martins Fontes, 2001.

WILLIANS, M.; BURDEN, R. L. Psychology for language teachers: a social constructivist approach. Cambridge: Cambridge University Press, 1997.

Recebido em: 16 jan. 2019 Aceito em: 6 ago. 2019 
